\title{
Perangkat Teknologi Digital Sebagai Media Simulasi Try Out Di Tingkat Sekolah Menengah Pertama
}

\author{
Arin Yuli Astuti ${ }^{1}$, Dyah Mustika Sari ${ }^{2}$, Nunung Rohmatun Novawati ${ }^{3}$ \\ Universitas Muhammadiyah Ponorogo \\ Jl. Budi Utomo No.10, Ronowijayan, Kec. Siman, Kabupaten Ponorogo, Jawa Timur \\ akademik@unmuh-ponorogo.org
}

\begin{abstract}
Today's digital technology is needed for daily needs. Everything that is processed and processed from resources can be solved with digital technology. Utilizing digital technology will save more costs than using it manually. In addition to downsizing the utilization of digital technology will also speed up the process and results of what is needed. The development of digital technology is currently very rapid, even from the world of education has implemented digital technology for learning. IT Ma'arif Bandar Pacitan Middle School is a private school that just took a computer-based exam in 2018. The test was carried out to join other schools. Ma'arif Bandar IT Middle School is a pilot private junior high school that has developed quite rapidly. However, due to lack of funds to have their own system, the try out practice exam still joins other schools. The researcher tries to make an application where students can run Try Out exams or practice exams independently. The research method for designing a tryout system is to use the Website Design Method (WSDM) method. The website design methodology was created to provide a systematic and scientific approach to website design. This application can later be used on computers or mobile phones. Utilization of digital technology using the Try Out application can benefit students and the school. In addition to using the official application from the government, the school and students can learn on their own by using this application.
\end{abstract}

Keywords: Try Out Application, WSDM, Computer Based Exams

\begin{abstract}
Abstrak
Teknologi digital saat ini sangat dibutuhkan untuk kebutuhan sehari-hari. Semua yang diolah dan diproses dari sumber daya dapat diselesaikan dengan teknologi digital. Dengan memanfaatkan teknologi digital akan lebih menghemat pengeluaran dibandingkan menggunakan secara manual. Selain berhemat pemanfaatan teknologi digital juga akan mempercepat proses dan hasil dari apa yang dibutuhkan. Perkembangan teknologi digital saat ini sangat pesat, bahkan dari dunia pendidikan sudah menerapkan teknologi digital untuk pembelajaran. SMP IT Ma'arif Bandar Pacitan adalah sekolah swasta yang baru melaksanakan ujian berbasis komputer tahun 2018. Ujian yang dilakasanakan bergabung ke sekolah lain. SMP IT Ma'arif Bandar merupakan SMP swasta rintisan yang memiliki perkembangan cukup pesat. Namun karena masih kurangnya biaya untuk memiliki sistem sendiri maka ujian latihan try out masih bergabung ke sekolah lain. Peneliti mencoba akan membuatkan sebuah aplikasi dimana para siswa dapat menjalankan ujian Try Out atau latihan ujian dengan mandiri. Metode penelitian untuk perancangan sistem ujian tryout adalah dengan menggunakan metode Website Design Method (WSDM). Metodologi perancangan website dibuat untuk memberikan pendekatan sistematis dan ilmiah untuk perancangan website. Aplikasi ini nantinya dapat digunakan di komputer maupun handphone. Pemanfaatan teknologi digital dengan menggunakan aplikasi Try Out dapat menguntungkan siswa maupun pihak sekolah. Selain menggunakan aplikasi yang resmi dari pemerintah, pihak sekolah dan siswa dapat belajar sendiri dengan menggunakan aplikasi ini.
\end{abstract}

Kata Kunci : Aplikasi Try Out, WSDM,Ujian Berbasis Komputer 


\section{PENDAHULUAN}

Teknologi digital saat ini sangat dibutuhkan untuk kebutuhan seharihari. Semua yang diolah dan diproses dari sumber daya dapat diselesaikan dengan teknologi digital. Dengan memanfaatkan teknologi digital akan lebih menghemat pengeluaran dibandingkan menggunakan secara manual. Selain berhemat pemanfaatan teknologi digital juga akan mempercepat proses dan hasil dari apa yang dibutuhkan. Perkembangan teknologi digital saat ini sangat pesat, bahkan dari dunia pendidikan sudah menerapkan teknologi digital untuk pembelajaran. Try out merupakan sebuah ujian coba yang dilaksakan sebelum ujian asli. Try out biasanya menggunakan soal-soal yang mirip dengan ujian asli agar siswa siap menghadapi ujian asli. Dengan menyelenggarakan ujian try out pengeluaran kertas akan sama dengan pengeluaran ujian asli. Dengan menggunakan ujian secara manual maka banyak yang harus dikeluarkan. Sistem koreksi dan pengiriman juga butuh waktu yang lama.

SMP IT Ma'arif Bandar Pacitan sekolah swasta yang baru melaksanakan ujian berbasis computer tahun 2018. Ujian yang dilakasanakan bergabung ke sekolah lain. SMP IT Ma'arif Bandar merupakan SMP swasta rintisan yang memiliki perkembangan cukup pesat. Namun karena masih kurangnya biaya untuk memiliki sistem sendiri maka ujian latihan try out masih bergabung ke sekolah lain. Peneliti mencoba akan membuatkan sebuah aplikasi dimana para siswa dapat menjalankan ujian Try Out. Aplikasi ini nantinya dapat digunakan di komputer maupun handphone. Pemanfaatan teknologi digital dengan menggunakan aplikasi Try Out dapat menguntungkan siswa maupun pihak sekolah. Selain menggunakan aplikasi yang resmi dari pemerintah, pihak sekolah dan siswa dapat belajar sendiri dengan menggunakan aplikasi ini. Dari hasil penelitian yang akan dilakukan maka dapat dirumuskan a) seberapa besar manfaat aplikasi Try Out untuk para siswa di SMP It Bandar?, b) seberapa besar pengaruh penggunakan aplikasi Try Out untuk meningkatkan kwalitas pengetahuan siswa? dan c) Bagaimanakah perbandingan setelah memiliki aplikasi try out mandiri dengan sebelum memiliki?. Tujuan penelitian yang akan dilakukan adalah memudahkan siswa dalam belajar mengerjakan soal-soal ujian dan dapat menambah wawasan anak dalam mengerjakan soal dibidang teknologi digital yang berdampak pada peningkatkan prestasi siswa

\section{METODOLOGI PENELITIAN}

Metode penelitian untuk perancangan sistem ujian tryout adalah dengan menggunakan metode Website Design Method (WSDM). Metodologi perancangan website dibuat untuk memberikan pendekatan sistematis dan ilmiah untuk perancangan website. Salah satu dari metodologi tersebut adalah Website Design Method (WSDM). Website Design Method (WSDM) yang dilafalkan dengan sebutan "WiSDoM" merupakan metode yang menggunakan audience-driven sebagai pendekatan. Metode diawali dengan 
mengidentifikasi perbedaan tipe pengguna. Kemudian, karakter dan informasi yang dibutuhkan setiap pengguna akan dideskripsikan [1].

a Mission Statement

Mission Statement Tahap pertama dalam WSDM adalah menentukan mission statement dari website yang akan dikembangkan. Mission statement ini paling tidak harus berisi tujuan, pokok informasi, dan sasaran pengguna. Tujuan dari pembuatan website akan memberikan dasar dalam pembuatan keputusan dan memberikan sedikit gambaran 8 mengenai website tersebut pada pengunjung. Sasaran pengguna merupakan pengguna yang ingin dituju atau yang akan tertarik pada website tersebut. Berhubungan dengan tujuan dan pengguna yang menjadi sasaran begitu juga dengan pokok informasi dari website. Pokok informasi yang disediakan pada website tersebut harus cocok dengan pengguna yang menjadi sasaran. Penting sekali melakukan identifikasi terhadap pokok informasi agar dikemudian hari tidak terjadi kebingungan informasi apa yang pantas dan tidak pantas dimasukkan.

b. Audience Modeling

Audience Modeling Secara umum, mission statement hanya memberikan indikasi umum mengenai pengguna yang menjadi sasaran. Bagaimanapun cakupan tersebut masih terlalu luas untuk menentukan apakah pengguna yang menjadi sasaran tersebut harus dimodelkan menjadi satu, dua atau lebih audience class.

c. Conceptual Design

Conceptual design berfokus pada konsep "apa dan bagaimana". Seperti pada perancangan basisdata dideskripsikan informasi apa saja yang akan ditampilkan (konsep "apa"), perbedaanya adalah pada fase ini akan dideskripisikan juga bagaimana struktur dari informasi tersebut nantinya dan bagaimana hubungan yang memungkinkan antar informasi tersebut (konsep "bagaimana"). Hal ini dibutuhkan karena hubugan antar informasi adalah karakteristik penting dari website. Jika hubugan antar informasi tersebut tidak dirancang dengan baik atau tidak cocok dengan pengguna yang menjadi sasaran, akan terjadi masalah usability yang serius (De Troyer, 2001). Conceptual design terbagi menjadi dua, yaitu: information modeling dan navigation design. Tujuan dari langkah information modeling adalah untuk memodelkan rancangan struktur data dari website yang akan dibuat. Alasan dari pemodelan sturktur data ini adalah keteraturan dan memudahkan maintenance. Dalam WSDM, hasil dari information modeling terbagi dalam beberapa skema konseptual yang berbeda, tidak seperti pada basisdata yang hanya memiliki satu skema konseptual. Hal ini disebabkan karena WSDM menggunakan pendekatan audience-driven. Pendekatan audience-driven diawali dengan pemodelan kebutuhan informasi untuk setiap audience class. Setelah selesai memodelkan kebutuhan informasi, selanjutnya akan dilakukan pemodelan terhadap kebutuhan fungsional. Langkah ini disebut dengan fungsional design. Pemodelan ini hanya berfokus pada kebutuhan fungsional saja (De 
Troyer \& Casteleyn, 2001). Langkah selanjutnya dari conceptual design adalah navigational design. Hasil dari langkah ini adalah navigational model yang akan terdiri dari beberapa navigation tracks, satu untuk setiap prerspektif. Sebuah navigation tacks menunjukkan bagaimana pengguna dengan perspektif tertentu dapat menelusuri semua informasi yang tersedia [2].

d. Implementation Design

Implementation Design Hal utama yang akan dilakukan pada fase ini adalah merancang "look and feel" website yang akan dikembangkan. Tujuannya adalah untuk membuat sesuatu yang konsisten, memuaskan, dan efisien untuk conceptual design yang telah dibuat pada fase sebelumnya. Hasil dari fase implementation design adalah implementation model.

e. Implementation Fase

Implementation Fase terakhir merupakan realisasi aktual pengembangan website dengan memilih suatu implementation environment. Sebagai contoh, apabila implementasi digunakana dengan HTML maka implementation model pada fase sebelumnya harus diubah kedalam source code HTML. Fase-fase dalam WSDM dapat dilihat pada Gambar berikut :

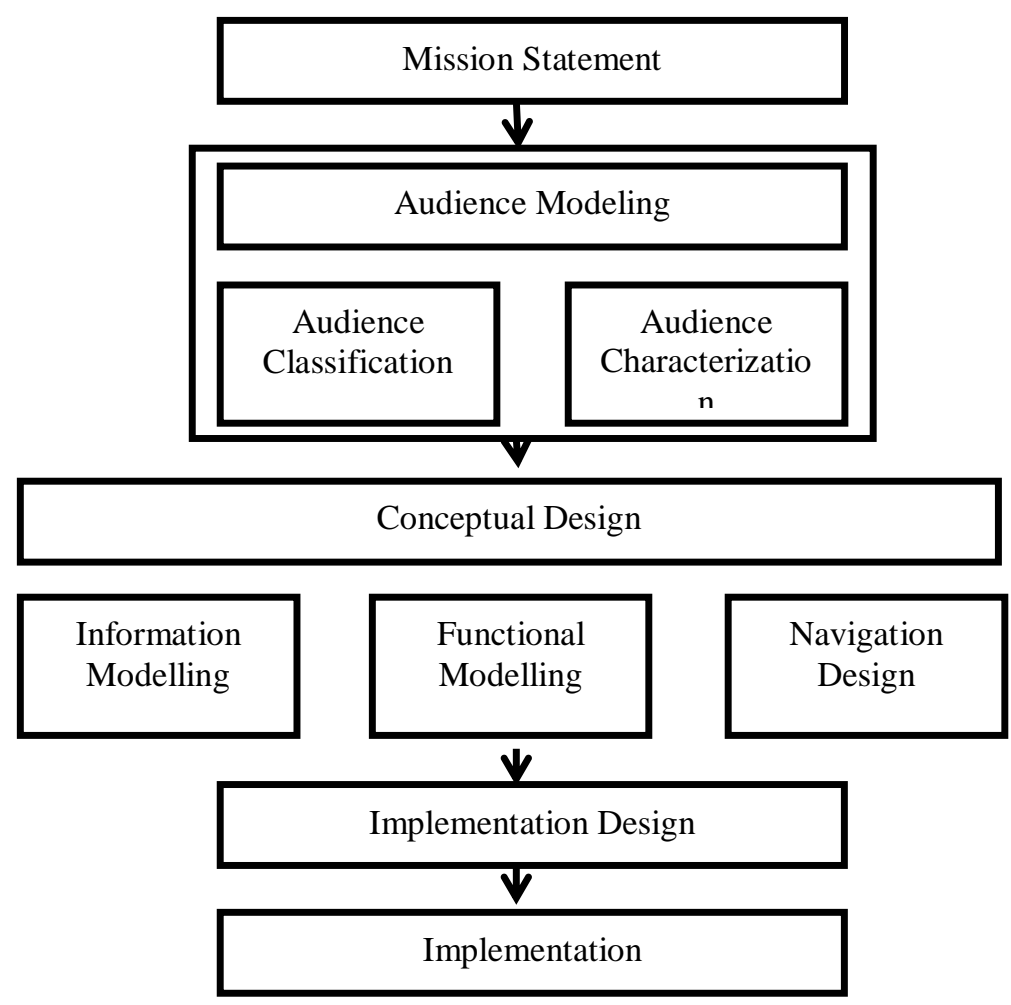

Gambar 1. Alur Fase WSDM 


\subsection{Peta Navigasi}

Adapun peta navigasi sistem ujian yang akan dibuat adalah sebagai berikut :

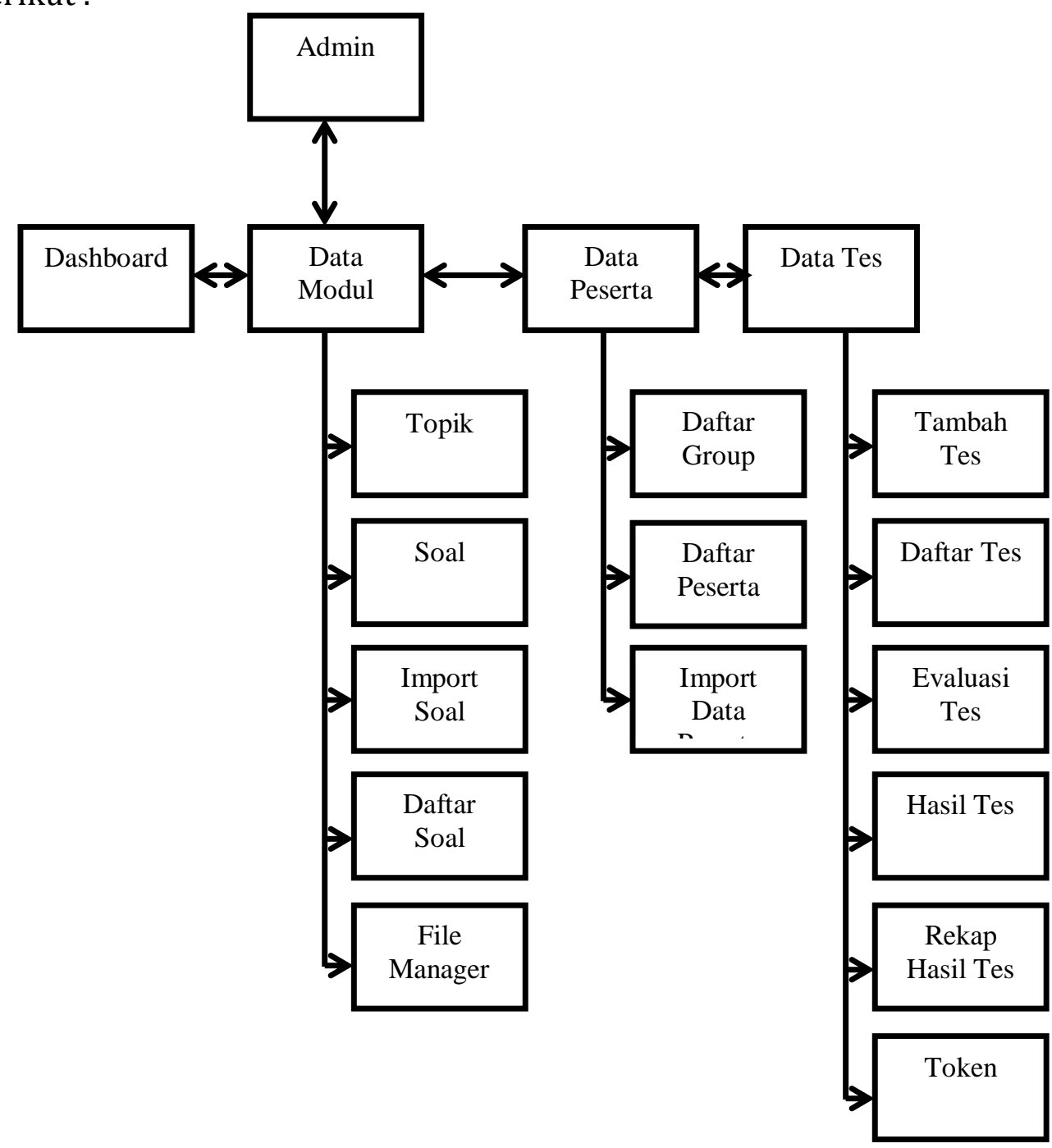

Gambar 2. Peta Navigasi

Keterangan :

a) Operator mulai login dan dapat mengakses menu modul, data tes, data peserta

b) Data Modul

Kelompok Data Modul digunakan untuk menambah modul, topik, dan soal. Serta digunakan untuk mengatur file dengan memanfaatkan File Manager. Yang terdiri dari Modul, Topik, Soal, Import Soal, Daftar Soal, File Manager

c) Data Peserta

Kelompok Data Peserta digunakan untuk mengatur Peserta, dan Group. Yang terdiri dari Daftar Group, Daftar Peserta, Import Data Peserta 
d) Data Tes

Kelompok Data Tes digunakan untuk mengatur Tes, mengevaluasi jawaban essay, dan melihat Hasil tes. Yang terdiri dari menu Tambah Tes, Daftar Tes, Evaluasi Tes, Hasil tes, Rekap Hasil Tes, Token

\section{HASIL DAN PEMBAHASAN}

Berikut bentuk tampilan aplikasi try out yang akan digunakan dalam latihan ujian nasional:

\section{a. Login untuk masuk dan mengerjakan soal Ty Out}

Masuk halaman login operator. Operator dapat memasukkan username dan password untuk bisa masuk ke menu utama.

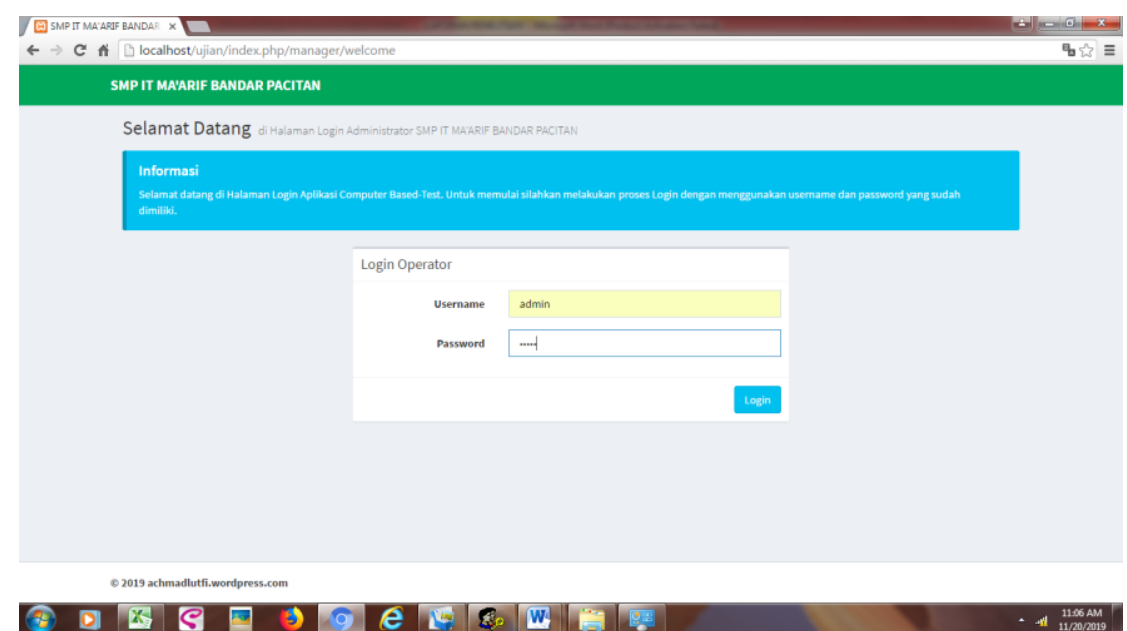

Gambar 3. Login Operator

\section{b. Tampilan Menu pada sistem}

Ada beberapa pilihan menu utama dalam sistem ujian yaitu Data modul, data peserta, data tes.

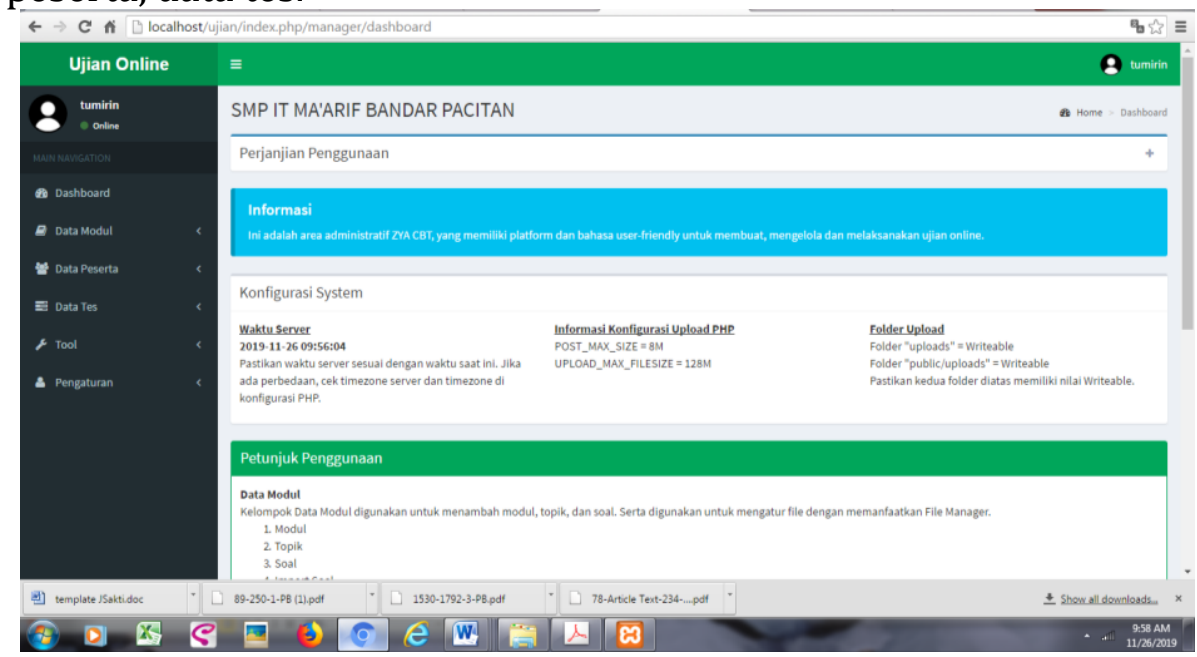

Gambar 4. Menu Utama Sistem 


\section{c. Tampilan Data Modul}

Didalam menu data modul terdapat sub menu diantaranya adalah : Topik, Soal, Import Soal, Daftar Soal, File Manager. Kelompok Data Modul digunakan untuk menambah modul, topik, dan soal. Serta digunakan untuk mengatur file dengan memanfaatkan File Manager.

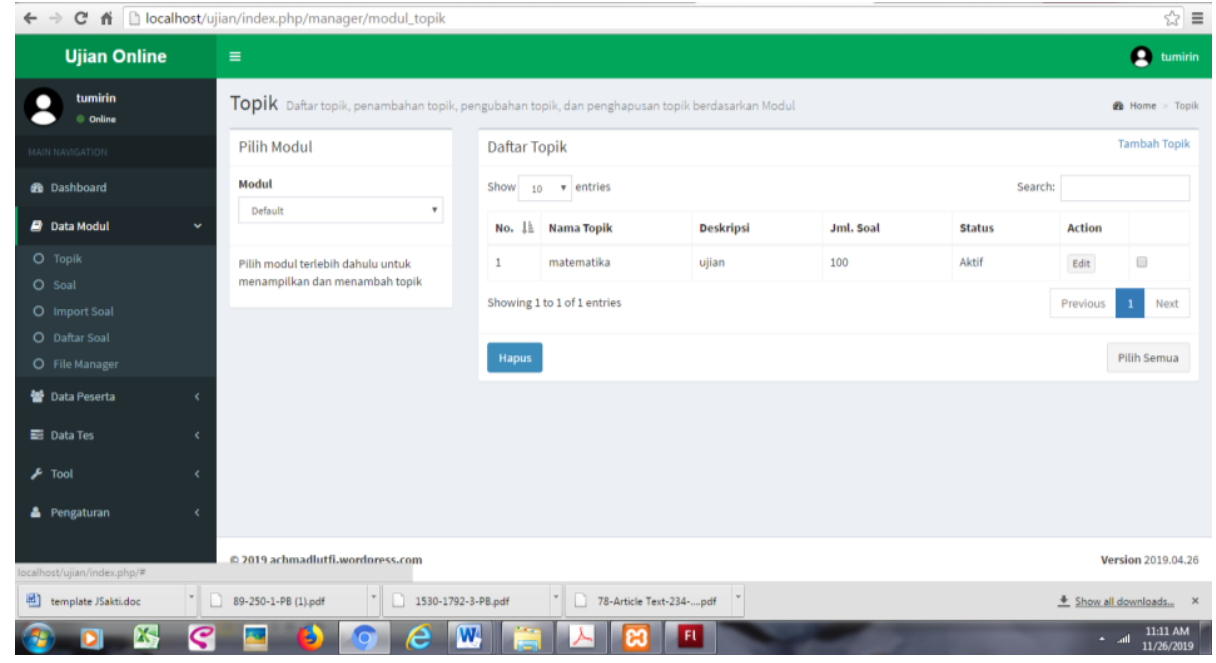

Gambar 5. Menu Utama Sistem

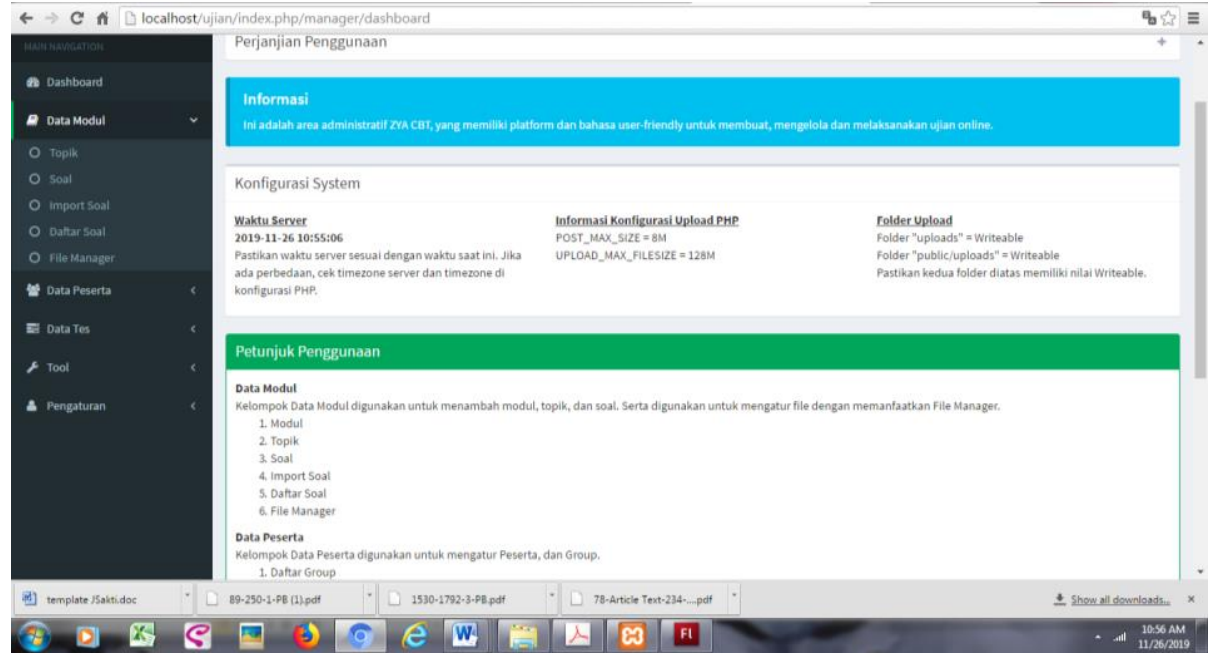

Gambar 6. Menu Data Modul

\section{d. Tampilan Data Peserta}

Didalam menu data peserta terdapat menu Daftar Group, Daftar Peserta, Import Data Peserta. Kelompok Data Peserta digunakan untuk mengatur Peserta, dan Group. 

ISSN: 2548-9771/EISSN: 2549-7200

http://tunasbangsa.ac.id/ejurnal/index.php/jsakti

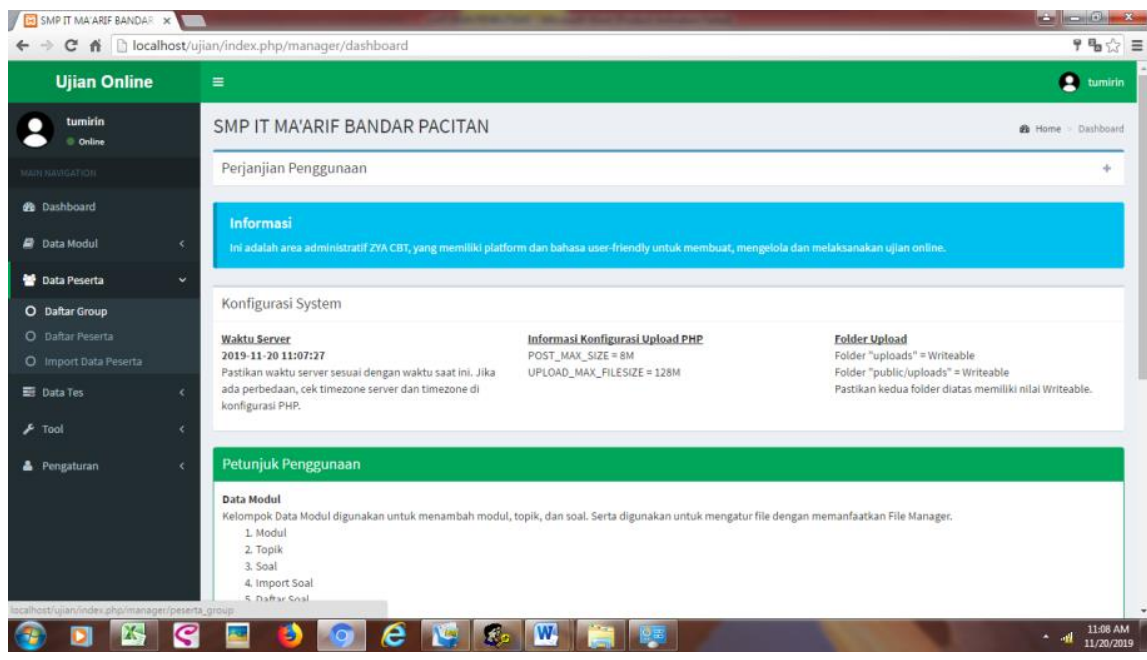

Gambar 7. Menu Data Peserta

\section{e. Menu Topik}

Operator dapat membuat topik pelajaran yang akan di unggah

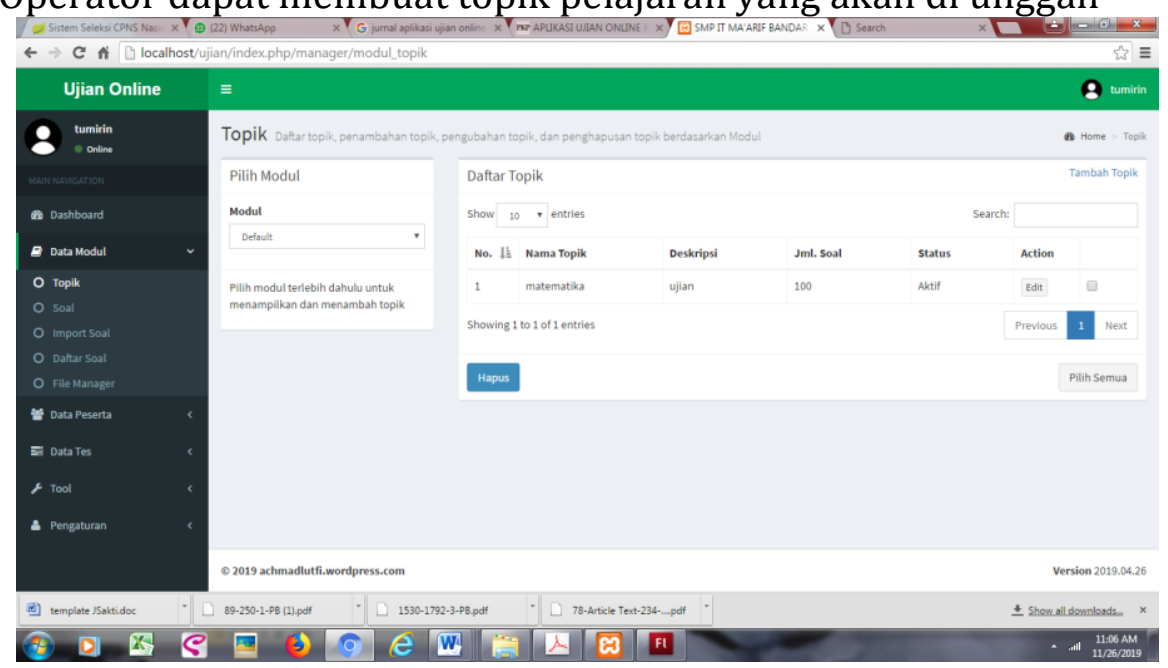

Gambar 8. Menu Daftar Topik

\section{f. Menu Import Soal}

Jika sudah mendaftarkan mata pelajaran maka operator dapat mengimportkan soal dan memilik menu matapelajaran yang sudah didaftarkan. 
Volume 4 Nomor 1 Maret 2020, pp. 38-48 ISSN: 2548-9771/EISSN: 2549-7200

http://tunasbangsa.ac.id/ejurnal/index.php/jsakti

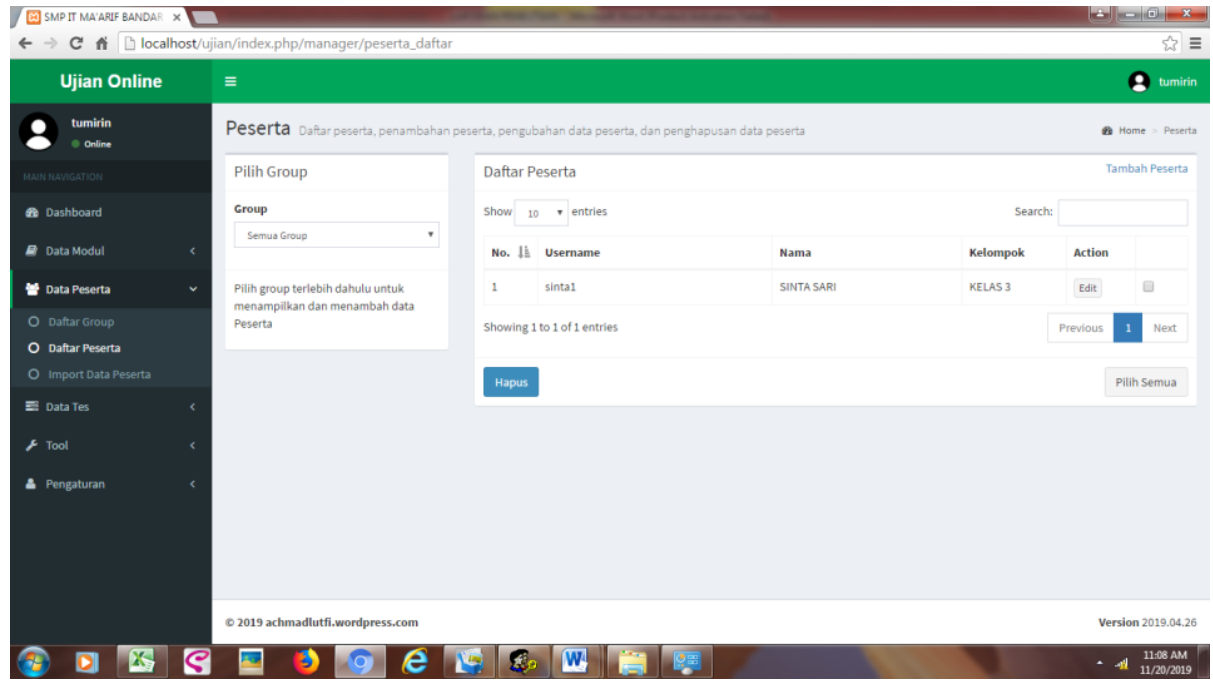

Gambar 9. Menu Import soal

\section{g. Menu Daftar Group}

Supaya dapat membedakan kelas maka operator dapat mendaftar group.

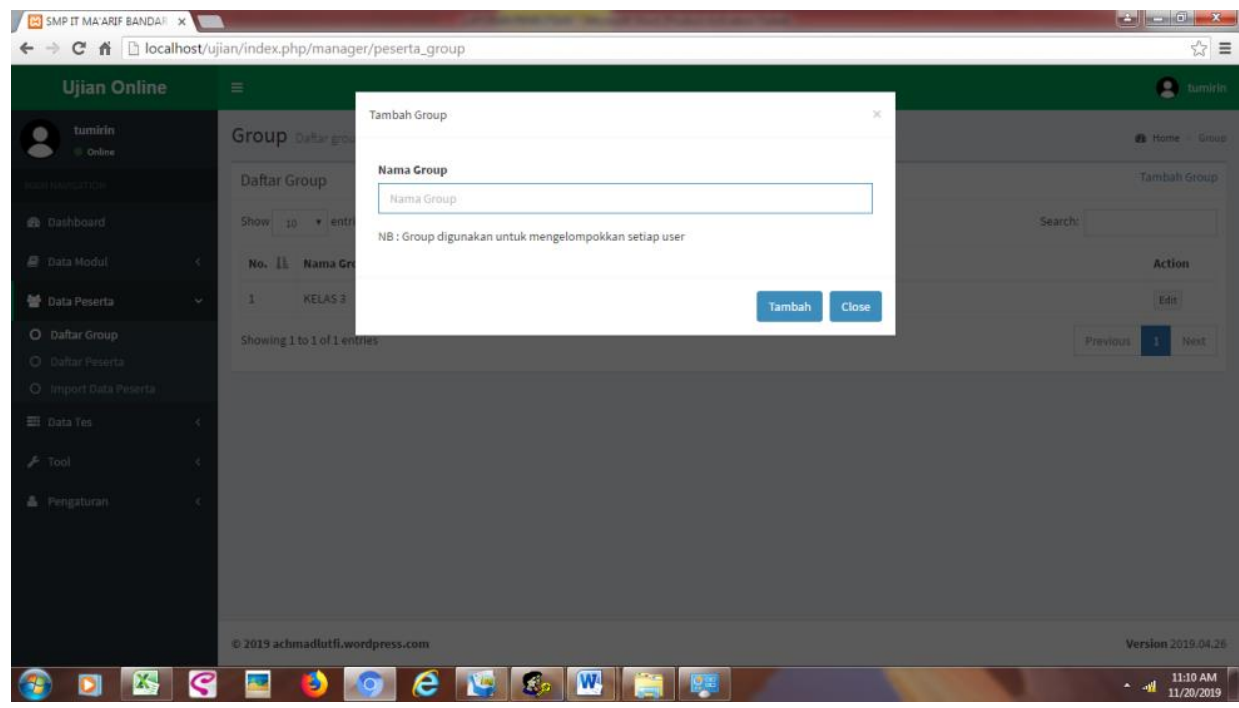

Gambar 10. Menu Daftar Group

\section{h. Menu Daftar Peserta}

Operator mendaftarkan siswa terlebih dahulu supaya dapat mengerjakan soal yang ada di sistem 


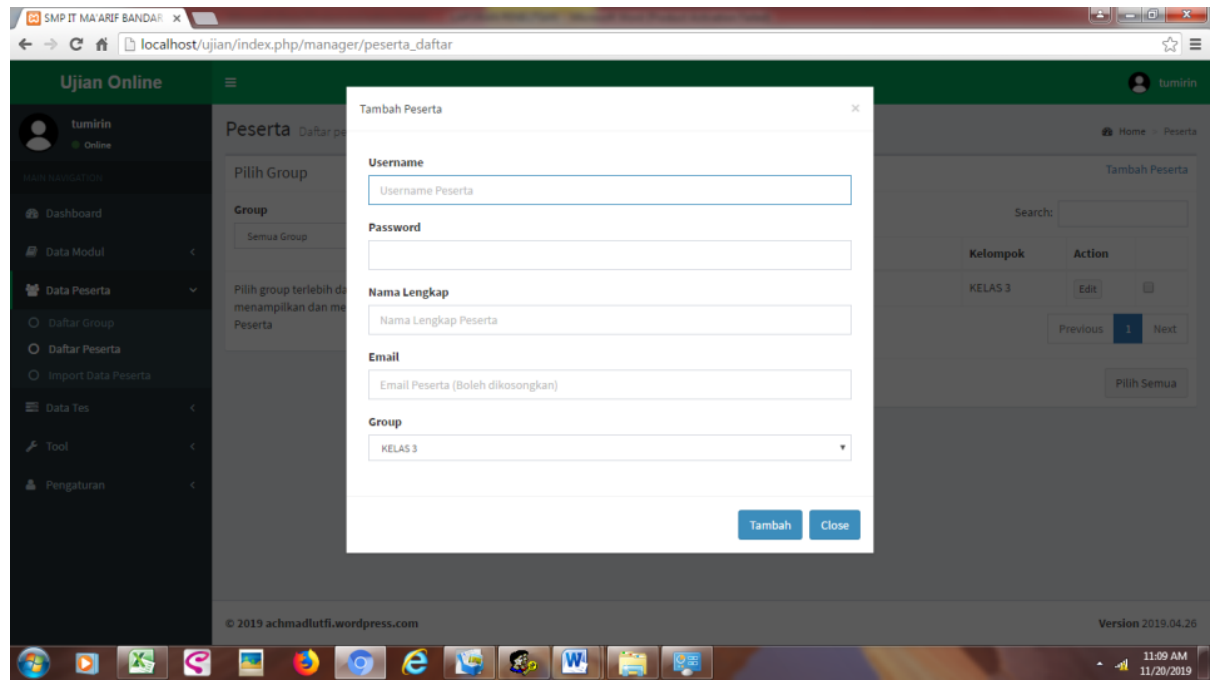

Gambar 11. Menu Daftar Peserta

\section{i. Menu Tambah Tes}

Untuk menu tambah tes operator dapat mengatur waktu, tanggal pengerjaan untuk soal yang akan di tampilkan

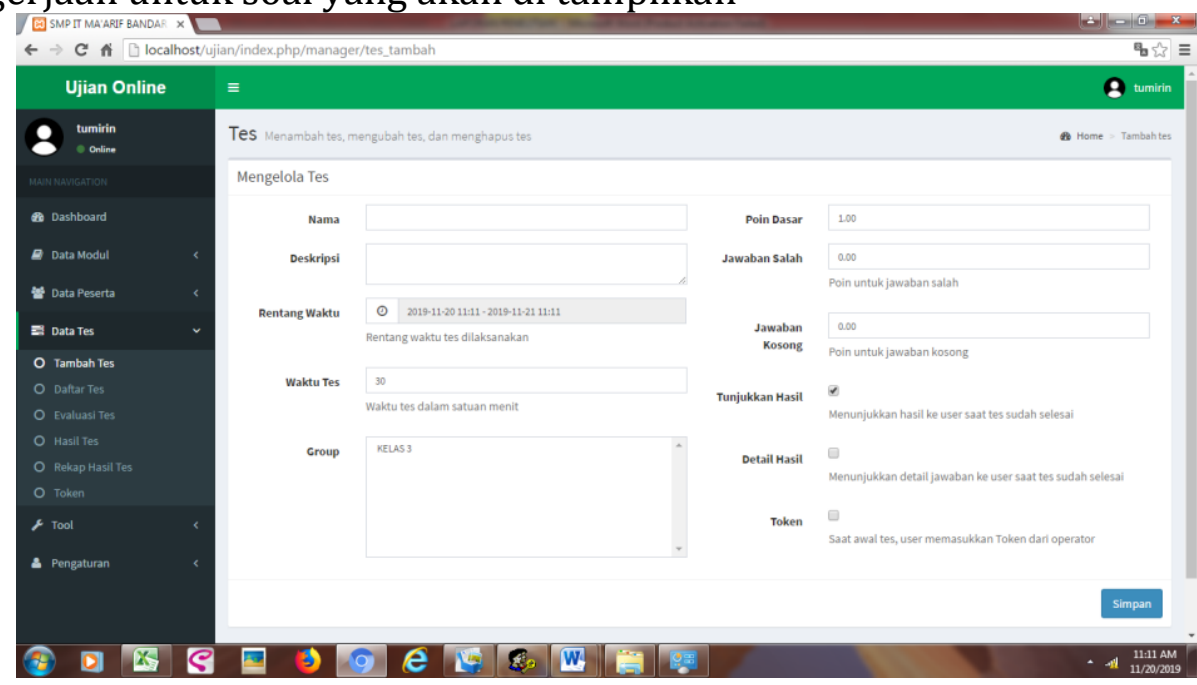

Gambar 12. Menu Tambah Tes

\section{SIMPULAN}

Kesimpulan dari sistem try out yang dibangun adalah dengan menggunakan aplikasi sistem ujian try out dapat membantu meningkatkan prestasi dari siswa yang akan menghadapi ujian nasional. Adapun saran yang diberikan untuk menigembangan sistem yaitu perlu adanya menu pengawas untuk mengkonfirmasi peserta yang masuk, supaya pengawas juga dapat mengabsen peserta yang mengikuti ujian. 


\section{DAFTAR PUSTAKA}

[1] De Troyer, O., dan Casteleyn, S. (2001, June). The conference review system with WSDM. Dalam First International Workshop on Web-Oriented Software Technology, IWWOST (Vol. 1).

[2] De Troyer, O., dan Leune, C. J. (1998). WSDM: a user centered design method for Web sites. Computer Networks and ISDN systems, 30(1), 85-94.Nana Syaodih Sukmadinata, Pengembangan Kurikulum Teori dan Praktek, (Bandung: PT. Remaja Rosdakarya, April 2013), hal. 67

[3] A partanto, Pius, dan Dahlan, M, Kamus Ilmiah Popular, (Surabaya: Arloka,2001), hlm.511.

[4] Sukismo,dkk, Erlangga Fokus UN SMP/MTs 2014...i

[5] Nana Syaodih Sukmadinata, Pengembangan Kurikulum Teori dan Praktek, (Bandung: PT. Remaja Rosdakarya, April 2013), hal. 67

[6] S. Eko Putro Widoyoko, Penilaian Hasil Pembelajaran Di Sekolahan, (Yogyakarta: Pustaka Pelajar, 2014), hlm.54. 